\title{
AGE DISTRIBUTION OF CARIES LESIONS IN CHILDREN'S PERMANENT TEETH - A BASIS FOR THE CHOICE OF A THERAPEUTIC SOLUTION
}

\author{
Milena Peneva, Maya Rashkova, Liliya Doychinova \\ Department of Pediatric Dentistry, Faculty in Dental Medicine, Medical Uni- \\ versity, Sofia, Bulgaria
}

\section{SUMMARY}

The object of the study is administered to the child the correlation between the reversible and irreversible caries lesions must be ascertained. A 1000 children aged 6-15, divided into 10 groups each comprising a hundred children, were subjected to epidemiological research.

Childhood and adolescence is characterised by an active and progressing caries process. The process is evinced in a big number of caries lesions at different stages of development. Many of the lesions are reversible nevertheless. The irreversible lesions are few in number, especially in the youngest patients. As the children grow older, the number of lesions increases, including the number fo irreversible lesions. This is indicative of the fact that no management of caries process has been administered, which makes it possible for the process to progress freely. The big share of reversible pathology makes it pretty obvious what should the character of medical treatment be. Reversible lesions can be cured non-operatively and preventively. Such a treatment requires systematic control of the caries process and a remineralisation non-operative treatment of the lesion. In this way full regeneration of the structure affected can be achieved which is the only adequate therapeutic approach.

Key words: caries lesions, children, therapeutic,

Permanent teeth begin to cut when a child is six. They find themselves in an oral environment having not yet undergone complete mineralisation and for about two years face the risk of developing caries $(1,2$,$) . A parallel risk at this$ age is the fact that the still existent temporary teeth have been already undergoing a progressing caries process. Children have caries lesions at this age many of which have not been cured. This is a precondition for the increase in the number of microorganisms causing caries which is a serious risk. Childhood goes hand in hand with a preference for sweet things and with a big and unwanted consumption of carbohydrates. Habits concerning oral hygiene have not been created yet or are not good enough. This puts the new permanent teeth at risk in a dangerous oral environment and causes the quick development of caries lesions $(6,7,9,11)$.
In the beginning the lesions are reversible and could be successfully treated non-operatively $(3,4,5,7,18)$. Modelling of the caries process as an illness followed by a remineralisation treatment is necessary if non-operative treatment is to be applied, though $(8,10,11,12)$.

In order that the necessary treatment is administered to the child the correlation between the reversible and irreversible caries lesions must be ascertained in the first place.

This is exactly the object of the study.

\section{MATERIALAND METHODOLOGY.}

A 1000 children aged 6-15, divided into 10 groups each comprising a hundred children, were subjected to epidemiological research. The research was conducted employing the following diagnostic terms: D0 - earliest possible changes visible after long drying and airing; D1 non-cavitated enamel lesion; D2 - cavitated enamel lesion; D3 - dentine lesion and D4 - complicated dentine lesion. For the statistical analysis average value, standard deviation and Ò-criterium of Student for comparison of two medium were used. An interval of verifiability of $95 \%$ was accepted.

\section{RESULTS AND DISCUSSION}

Diagram No 1. Age distribution of caries lesions in children's permanent teeth

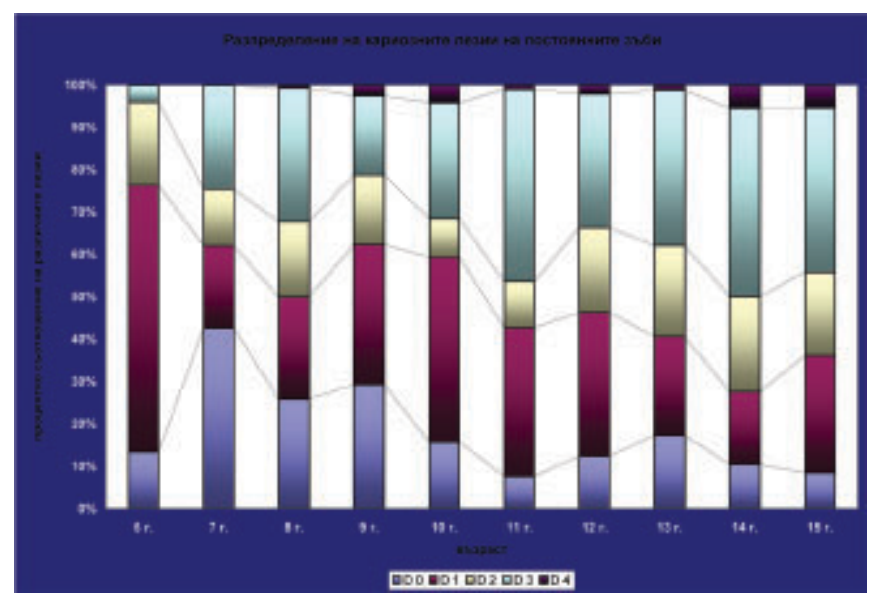


In this diagram the correlation between the different degrees of caries lesions in the permanent teeth of children aged 6-15 is represented. The so-called Nyvad ,iceberg” of the caries pathology can be seen here. The diagram shows that the tip of the iceberg are the irreversible lesions D3 and D4. These are the irreversible dentine caries and the complications from the caries that have affected the pulp or the periodoncium. These two stages are the smallest part of the pathology. Hence their being at the top of the iceberg. They are what we clearly see during a routine checkup. They cannot be identified with the caries process, though. As is the case with each lesion observed, they are just a symptom of the process causing caries. They are a reminder of our inactivity as the process unfolds. If we only restrict ourselves to dealing with this tip of the iceberg, we are doomed to keep fighting its consequences as the process intensifies and broadens thus making operative treatment inefficient. Radical measures are increasingly applied making the treatment of the patient a much harder, much less likely to succeed and much more expensive a job.

We must look under the tip of the iceberg, though. There we can see the broad foundation of the pathology. It is comprised of a big number of reversible lesions. It is lesions that can be easily, painlessly, unexpensively and kindly influenced. It is a possibility for us to display our professionalism as true healers, whose actions bring about recuperation and not about repair with artificial substitutes.

Diagram No 2. „Iceberg” of the caries pathology within the group of 15-year old children

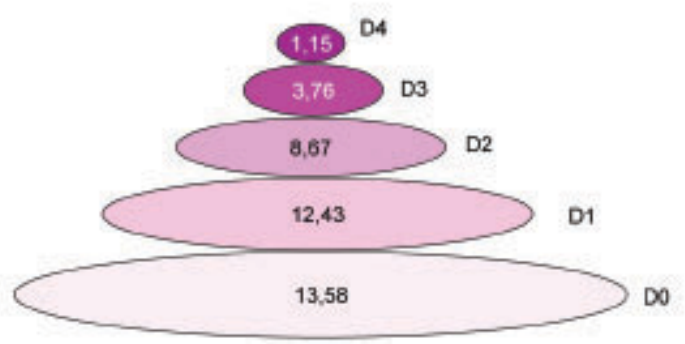

The "iceberg" is created by the progressive arrangement of the pathology discovered according to the degree of its progression. The basis of the iceberg is the broadest part. It is created by diagnostic band D0. At this diagnostic level the earliest visible manifestations of the caries process are detected. In order that such a level of diagnostics is achieved, clear classification criteria, thorough visual examination, good lighting, careful drying and airing, as well as modern equipment must be applied. The next level of the iceberg comprises the lesions detected within diagnostic band D1. It is the clearly visible reversible stages in the development of the early caries process that we usually call white spots. The amount of pathology monitored here is much smaller since the very early stages in the process of caries have already been detected within diagnostic band D0. The next level of diagnosing is aimed at weighing the cavitated white enamel lesions. This is diagnostic band D2. At this stage of diagnostication the pathology detected is partly reversible. Then comes another level of the iceberg. It is diagnostic band D3 which comprises the dentine lesions. A small part of the dentine lesions on the surface of the enamel are potentially reversible. Lesions at this level are usually considered irreversible. There is evidence already that part of these lesions - the ones situated around the enameldentine border or on the surface of the dentine - can be cured. This shows that even part of the lesions within that level must not be immediately subjected to operative treatment. A careful analysis of the extent to which the dentine has been affected has to be conducted. Accordingly, if possible, non-operative treatment must be administered. The last level - embracing lesions D4 - is there to accentuate the occurrence of complications from the caries process. Such complications are least common in childhood and are completely irreversible.

Considering the whole range of the pathology occurring allows us to arrive at a couple of important findings. The first one is that much of the pathology is reversible. Hence the need for a change in our way of thinking and acting as specilists. The second finding is that the criteria for determining the dental pathology in the examinations we conduct - whether epidemiological or individual - should be precise and clear enough to allow us to detect the reversible stages in the caries process. The third finding is that both routine daily diagnosing and epidemiological research should be backed up by supplementary diagnostic instruments so that the smallest changest - which are also the most easily reversible ones - could be detected. Such an approach to diagnostication would allow for a better control of the risk environment at each moment in time. We must bear in mind that the caries is not simply the lesion we observe. The process itself has begun before the emergence of the lesion. And this process is the result from a disturbance in balance of the various risk factors.

And there is a finding that summarises the previous ones. It is the finding that the irreversible pathology is just the tip of the iceberg. This tip is very small but we must not be misled by that. However small the tip of the iceberg the health status of our children is not good. Diagnostic level D3 only allows us to determine the irreversible pathology and leads us into neglecting the irreversible stages in the process of caries. And it is precisely these stages that comprise the massive foundation of the iceberg. 


\section{CONCLUSION:}

Childhood and adolescence in our country is characterised by an active and progressing caries process. The process is evinced in a big number of caries lesions at different stages of development. Many of the lesions are reversible nevertheless. The irreversible lesions are few in number, especially in the youngest patients. As the children grow older, the number of lesions increases, including the number fo irreversible lesions. This is indicative of the fact that no management of caries process has been administered, which makes it possible for the process to progress freely $(13,14$, $15,16,17)$. The big share of reversible pathology makes it pretty obvious what should the character of medical treatment be. Reversible lesions can be cured non-operatively and preventively. Such a treatment requires systematic control of the caries process and a remineralisation non-operative treatment of the lesion. In this way full regeneration of the structure affected can be achieved which is the only adequate therapeutic approach.

\section{Conclusions:}

1. In childhood and adolescence reversible lesions prevail which can be treated preventively and non-operatively;

2. Irreversible lesions requiring operative treatment are few in number;

3. At this age the appropriate therapeutic approach is non-operative preventive treatment.

\section{REFERENCES:}

1. Mateeva Kh. et al. [Epidemiological study of the caries of permanent teeth in children and adolescents in Plovdiv and the Plovdiv district.] Stom. (S). 1991; 73(2):49-52. [in Bulgarian]

2. Mateeva Kh. et al. [Caries incipiens in childhood. Clinical, epidemiological, morphological and prophylactic and curative aspects] two volumes. [doctoral thesis] Plovdiv, Stomatological Faculty. 1995. [in Bulgarian]

3. Anderson MH, Bales DJ, Omnell KA. Modern management of dental caries: the cutting edge is not the dental bur. J Am Dent Assoc. 1993 Jun;124(6):36-44. [PubMed]

4. Axelsson P. New ideas and advancing technology in prevention and non-surgical treatment of periodontal disease. Int Dent J. 1993 Jun;43(3): 223-38. [PubMed]

5. Axelsson P. An Introduction to Risk Prediction and Preventive Dentistry. 1st Edition. Quintessence Pub Co. October 15, 1999. 1-7

6. Bader JD, Shugars DA, Bonito AJ. Systematic reviews of selected dental caries diagnostic and management methods. J Dent Educ. 2001 Oct; 65(10):960-8. [PubMed]

7. Bader JD, Shugars DA, Bonito AJ.
A systematic review of selected caries prevention and management methods. Community Dent Oral Epidemiol. 2001 Dec;29(6):399-411. [PubMed] [CrossRef]

8. Baelum V, Fejerskov O. Caries diagnosis: A mental resting place on the way to intervention? In: Dental Caries - The Disease and Its Clinical Management. Fejerskov O, Kidd E. (eds). London, Blackwell Munksgaard, 2003. pp 101-110.

9. Baelum V, Machiulskiene V, Nyvad B, Richards A, Vaeth M. Application of survival analysis to carious lesion transitions in intervention trials. Community Dent Oral Epidemiol. 2003 Aug;31(4):252-60. [PubMed] [CrossRef]

10. Balevi B. The management of incipient or suspicious occlusal caries: a decision-tree analysis. Community Dent Oral Epidemiol. 2008 Oct;36(5): 392-400. [CrossRef]

11. Edelstein BL, Douglass CW. Dispelling the myth that 50 percent of U.S. schoolchildren have never had a cavity. Public Health Rep. 1995 SepOct;110(5):522-30. [PubMed]

12. Edelstein BL. The Medical Management of Dental Caries. J Am
Dent Assoc. 1994 Jan;125(1 Suppl): 31S-39S. [CrossRef]

13. Featherstone JD, Adair SM, Anderson MH, Berkowitz RJ, Bird WF, Crall JJ, et al. Caries management by risk assessment: consensus statement, April 2002. J Calif Dent Assoc. 2003 Mar;31(3):257-69. [PubMed]

14. Featherstone JD, Gansky S, Hoover $\mathrm{C}$, et al. A randomized clinical trail of caries management by risk assessment. Caries Res. 2005; 39:295.

15. Featherstone JD. Caries prevention and reversal based on the caries balance. Pediatr Dent. 2006 MarApr;28(2):128-32. [PubMed]

16. Fejerskov O, Kidd E. Dental caries, the disease and its clinical management. Bleckwell, Munksgaard, 2004.

17. Ismail AI, Hasson H, Sohn W. Dental caries in the second millennium. J Dent Educ. 2001 Oct;65(10):953-9. [PubMed]

18. Ismail AI, Brodeur JM, Gagnon P, Payette M, Picard D, Hamalian T, et al. Prevalence of non-cavitated and cavitated carious lesions in a random sample of 7-9-year-old schoolchildren in Montreal, Quebec. Community Dent Oral Epidemiol. 1992 Oct;20(5):250-5. [PubMed] [CrossRef]

\author{
Adress for corespondense: \\ Milena Peneva \\ Department of Pediatric Dentistry, Faculty of Dental Medicine, \\ 1, G. Sofiiski str., 1431 Sofia, Bulgaria \\ E-mail: milenapeneva@mail.bg
}

